Article

\title{
Studies on Transition Metal-Quercetin Complexes Using Electrospray Ionization Tandem Mass Spectrometry
}

\section{Yuanzhen Liu ${ }^{1}$ and Mingquan Guo ${ }^{1,2, *}$}

1 Key Laboratory of Plant Germplasm Enhancement and Specialty Agriculture, Wuhan Botanical Garden of Chinese Academy of Sciences, Wuhan 430074, China; E-Mail: lyz19851001@wbgcas.cn

2 The Keck School of Medicine, University of Southern California, Los Angeles, CA 90089, USA

* Author to whom correspondence should be addressed; E-Mail: guomq@wbgcas.cn; Tel./Fax: +86-27-8751-8018.

Academic Editor: Derek J. McPhee

Received: 8 April 2015 / Accepted: 5 May 2015 / Published: 13 May 2015

\begin{abstract}
To systematically study the effects of the number of $d$ electrons of the first transition metal ions ( $\mathrm{Fe}, \mathrm{Co}, \mathrm{Ni}, \mathrm{Cu}$ and $\mathrm{Zn}$ ) on the formation and stability of metal flavonoid complexes, we took the quercetin/ $\mathrm{M}^{2+}$ complex as a model system to investigate the structures and properties of these complexes. Based on considerable structural information obtained through ESI-MS ${ }^{\mathrm{n}}$, all of the first transition metal ions $\left(\mathrm{Fe}^{2+}, \mathrm{Co}^{2+}, \mathrm{Ni}^{2+}\right.$, $\mathrm{Cu}^{2+}$ and $\mathrm{Zn}^{2+}$ ) were found to form different complexes with quercetin, while with the number of chelating flavonoids decreasing along with the reduction of the metal ionic radius. Quercetin forms different complexes with the above metal divalent ions through its 5-OH and 4-carbonyl groups; the complex stability is highly dependent on both the metallic ion and the flavonoid chelator itself. As for the central ion $\left(\mathrm{M}^{2+}\right)$, when chelated with quercetin to form the complex, the stability of the complex decreased in the following order: $\mathrm{Cu}^{2+}>$ $\mathrm{Ni}^{2+}>\mathrm{Co}^{2+}>\mathrm{Fe}^{2+}>\mathrm{Zn}^{2+}$. With flavonoid: metal stoichiometries at 2:1, the complexes formed between quercetin and metal ions $\left(\mathrm{Fe}^{2+}, \mathrm{Ni}^{2+}, \mathrm{Co}^{2+}\right.$ and $\left.\mathrm{Zn}^{2+}\right)$ have the similar fragmentation mechanism, while $\mathrm{Cu}^{2+}$ displayed different fragmentation mechanism due to the concurrent oxidation.
\end{abstract}

Keywords: flavonoid; ESI-MS ${ }^{\text {; }}$ metal complexes; CID; fragmentation mechanism 


\section{Introduction}

Flavonoids are a class of widely spread plant secondary metabolites that have shown promising anti-oxidant, anti-virus, anti-inflammatory and anti-cancer activities [1,2]. In general, the anti-oxidant mechanisms of flavone compounds are mainly due to their ability to scavenge free radicals. Another mechanism may result from the interactions between flavonoids and transition metal ions to form complexes that prevent the participation of metal ions in free radical generating processes, thus exhibiting an anti-oxidant behavior [3]. Recent studies indicated that metal-flavonoid complexes have good biological and pharmacological activities, and some of which have been successfully used in clinical practices [4,5]. Meanwhile, the flavonoids, as natural metal chelators, have also played significant roles in metal bio-utilization and reduction of heavy metal toxicity, and may suppress the Fenton response and lipid peroxidation [6]. The coordination of flavonoids with $\mathrm{Cu}^{2+}, \mathrm{Mn}^{2+}$, or $\mathrm{Fe}^{2+}$ metallic ions, may simulate the catalyzed center of the hyperoxide dismutase in the metal coordinate structure, thus displayed the superoxide dismutase (SOD) activity [7]. Therefore, research on the metal flavonoid complexes is very helpful in developing new medicines, based on these complexes and exploring new ways in screening, discovery and development of new drugs.

Quercetin (3,3',4',5,7-pentahydroxyflavone) is one of the most bioactive and common dietary flavonoids, which widely exists in the flowers, leaves, and fruits of many plants. However, due to its poor solubility, quercetin was found to be difficult to be absorbed into the body, thus resulted in poor bioavailability in vivo. Fortunately, it has been reported that quercetin can form complexes with transition metal ions, such as $\mathrm{Cu}^{2+}, \mathrm{Mn}^{2+}$ and $\mathrm{Fe}^{2+}$. These quercetin-metal complexes exhibit broad biological activities with increasing bioavailability, such as anti-oxidation, anti-bacterial, anti-tumor, and the ability to affect many kinds of enzymatic activities [8-11]. Not only can these quercetin/metallic ion complexes enhance its bioavailability and change the way to deliver quercetin in vivo, but they also promote new pharmacological activity (e.g., SOD activity) [12-14]. Although the traditional methods (e.g., UV/Vis and IR absorption spectroscopy, Raman spectra) have been used to elucidate the structures of metal flavonoid complexes in numerous studies, they can only give indirect evidence for flavonoidtransition metal complexation [15-22]. Recently, electrospray ionization tandem mass spectrometry (ESI-MS) has become a powerful tool in the analysis of metal-flavonoid complexes [23,24], which could provide abundant fragment information for the characterization of those complex labile structures, such as the most important information regarding the stoichiometry and chelating sites of the metallic complexes [25-27]. By using soft ionization mass spectrometry, the first systematic investigation on the complexes between quercetin and five kinds of first transition metal ions $\left(\mathrm{Fe}^{2+}, \mathrm{Co}^{2+}, \mathrm{Ni}^{2+}, \mathrm{Cu}^{2+}\right.$ and $\mathrm{Zn}^{2+}$ ) was conducted in this study, and showcased the power and potential wide applicability of this strategy for the in-depth characterization of metallic complexes.

\section{Results and Discussion}

To systematically study the effects of the number of $d$ electrons of the first transition metals (Fe, $\mathrm{Co}, \mathrm{Ni}, \mathrm{Cu}$ and $\mathrm{Zn}$ ) on the formation and stability of metal flavonoid complexes, quercetin/ $\mathrm{M}^{2+}$ complexes were chosen as a model system to investigate the structure and properties of these metallic complexes. Although the formation of transition metal-flavonoid complexes is quite complicated, 
$\mathrm{ESI}^{\mathrm{M}} \mathrm{M}^{\mathrm{n}}$ can be used to detect the formation of metal-flavonoid complexes in solution with high sensitivity. The chemical structures of quercetin can be found in Scheme 1 ("Q" denotes quercetin hereafter). The positive scan mode was used throughout the mass spectrometric experiments. Collision-induced dissociation (CID) spectra were obtained by selecting a given complex with the stoichiometry of 2:1 in the first quadrupole and transferring it into the collision cell with argon. In order to optimize the conditions, the pressures and the voltages applied to the collision cell were tuned in the ranges of (1-4) $\times 10^{-3} \mathrm{mBar}$ and $20-60 \mathrm{eV}$, respectively.

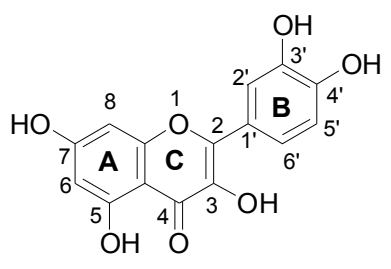

I

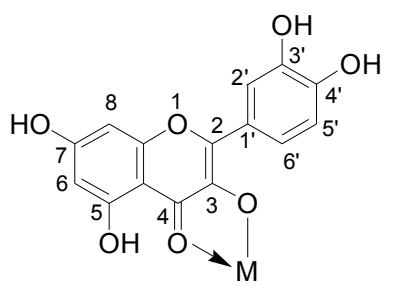

III

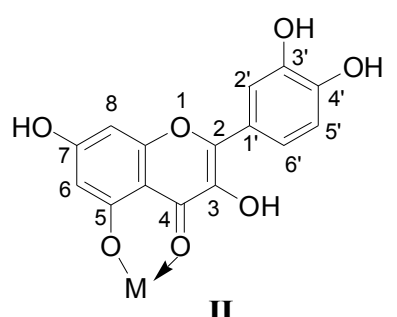

II

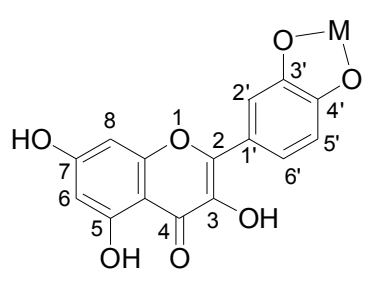

IV

Scheme 1. Structures of Quercetin and its proposed chelating complexes with $\mathrm{M}^{2+}$.

\subsection{Full-Scan ESI-MS Analysis of $M^{2+} /$ Quercetin Complexes}

The full-scan mass spectra of quercetin-metal complex were shown in Figure 1. Two quercetin-Fe complexes are observed in Figure 1a, where peak A was shown at $\mathrm{m} / \mathrm{z} 658$ and peak B at $\mathrm{m} / \mathrm{z} 1012$. According to their molecular weights, it was deduced that complex A corresponded to [(2Q-H)Fe $]^{+}$ (molar ratio of $\mathrm{Q} / \mathrm{Fe}=2: 1$ ), and complex $\mathrm{B}$ was in agreement with $\left[(3 \mathrm{Q}-3 \mathrm{H}) \mathrm{Fe}_{2}\right]^{+}$(molar ratio of $\mathrm{Q} / \mathrm{Fe}=3: 2)$. Similarly, peak $\mathrm{D}(\mathrm{m} / \mathrm{z} 662)$ and $\mathrm{E}(\mathrm{m} / \mathrm{z} 1020)$ in Figure $1 \mathrm{~b}$ were corresponding to the quercetin-Co complexes $[(2 \mathrm{Q}-\mathrm{H}) \mathrm{Co}]^{+}($molar ratio of $\mathrm{Q} / \mathrm{Co}=2: 1)$ and $\left[(3 \mathrm{Q}-3 \mathrm{H}) \mathrm{Co}_{2}\right]^{+}$(molar ratio of $\mathrm{Q} / \mathrm{Co}=3: 2$ ), and the quercetin-Co complex also showed methanol and water adducts (peak C) at $m / z$ $409\left(\left[\mathrm{Co}\left(\mathrm{H}_{2} \mathrm{O}\right)\left(\mathrm{CH}_{3} \mathrm{OH}\right) \mathrm{Q}\right]^{+}\right)$. In Figure 1d, redox reaction through the change of oxidation state of $\mathrm{Cu}$ was observed in our experiment, in which peaks $\mathrm{F}$ and $\mathrm{G}$ represented the quercetin-Cu complexes $\left[\mathrm{Cu}\left(\mathrm{Q}^{*}\right)\right]^{+}$(molar ratio of $\left.\mathrm{Q} / \mathrm{Cu}=1: 1\right)$ and $\left[\mathrm{Cu}\left(2 \mathrm{CH}_{3} \mathrm{OH}\right)\left(2 \mathrm{Q}^{*}\right)\right]^{+}$(molar ratio of $\mathrm{Q} / \mathrm{Cu}=2: 1$ ), respectively $\left(\mathrm{Q}^{*}\right.$ denotes oxidized quercetin). The peak at $\mathrm{m} / \mathrm{z} 303$, corresponding to protonated quercetin $\left([\mathrm{Q}+\mathrm{H}]^{+}\right)$was found in all three positive full-scan mass spectra (Figure 1a-c). In addition, most of the other related peaks were also inferred and labeled in Figure 1. However, the chloride adducts have not been observed in the positive ion mode under our experimental conditions, and those adducts may be more easily observed in the negative ion mode. 


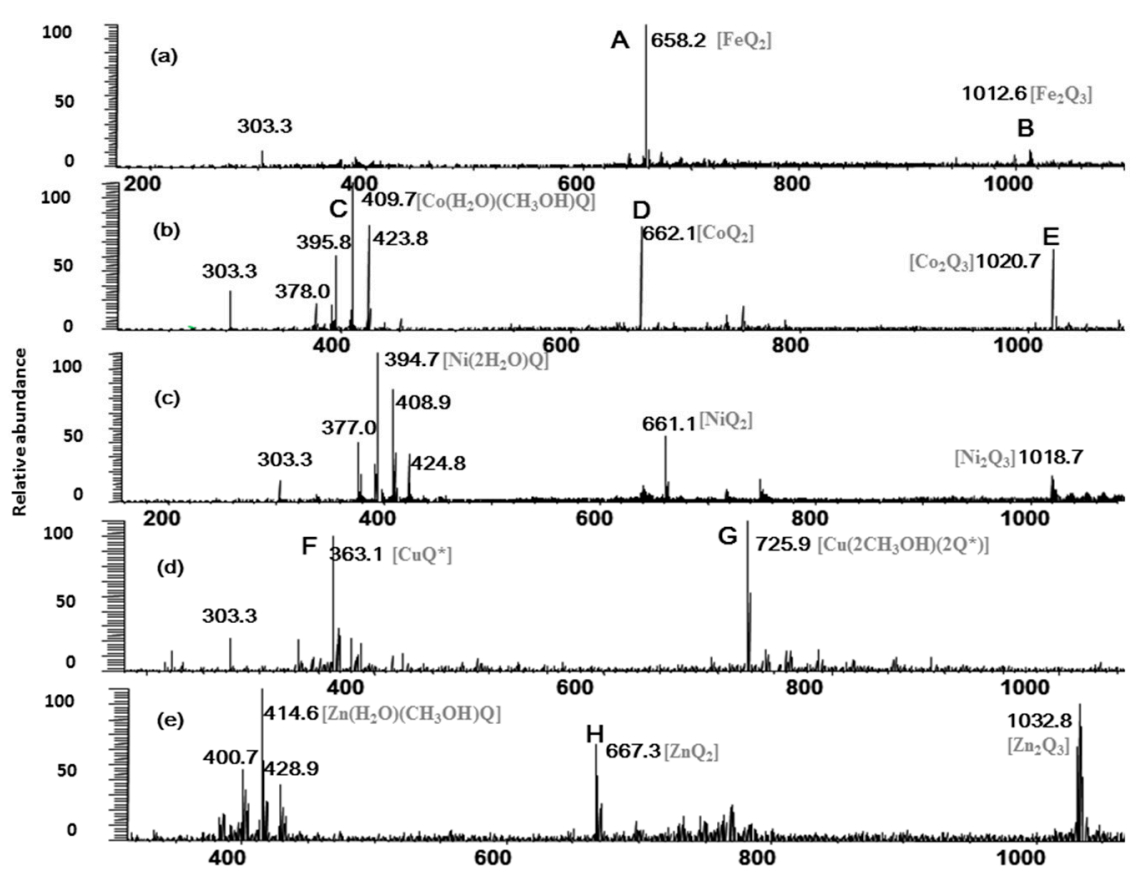

Figure 1. Full scan mass spectrum of the quercetin $/ \mathrm{M}^{2+}$ complexes $\left(\mathrm{Q}^{*}\right.$-oxidized quercetin).

(a)-(e) for quercetin-Fe, $-\mathrm{Co},-\mathrm{Ni},-\mathrm{Cu}$, and $-\mathrm{Zn}$ complexes, respectively.

From the full-scan mass spectra, several conclusions could be drawn. First, $\mathrm{Fe}^{2+}$ and quercetin mainly formed metal-flavonoid complexes with stoichiometry of 1:2 and a few complexes with stoichiometry of 2:3, while $\mathrm{Cu}^{2+}$ and quercetin formed complexes with stoichiometries 1:1 and 1:2. Secondly, $\mathrm{Co}^{2+}$, $\mathrm{Ni}^{2+}, \mathrm{Zn}^{2+}$ and quercetin formed metal-flavonoid complexes with stoichiometries of 1:1, 1:2 and 2:3. This indicated that $\mathrm{Co}^{2+}, \mathrm{Ni}^{2+}, \mathrm{Zn}^{2+}$ were easier to form metal-flavonoid complexes with higher stoichiometries than those of $\mathrm{Cu}^{2+}$, and they are in the following order: $\mathrm{Fe}^{2+}>\mathrm{Zn}^{2+}>\mathrm{Co}^{2+}>\mathrm{Ni}^{2+}>\mathrm{Cu}^{2+}$. We thus conclude that the first transition metallic ions (II) including $\mathrm{Fe}, \mathrm{Co}, \mathrm{Ni}, \mathrm{Cu}$ and $\mathrm{Zn}$ can all form the different complexes with quercetin, and the number of chelating flavonoids decreases along with reduction of the five kinds of the first transition metal ionic radius. The reported metal ionic radius, number of $d$ electrons, crystal field stabilization energies (CFSE) and other parameters [28] were shown in Table 1.

Table 1. The ionic radius, number of $d$ electrons and CFSE of the first transition metals.

\begin{tabular}{ccccc}
\hline Metal Ion & Number of $\boldsymbol{d}$-electrons & Metal $\boldsymbol{R}$. & Space Configuration & CFSE(Dq) \\
\hline $\mathrm{Fe}^{2+}$ & $\mathrm{d}^{6}$ & $75 \mathrm{pm}$ & Octahedron & -4 \\
$\mathrm{Co}^{2+}$ & $\mathrm{d}^{7}$ & $72 \mathrm{pm}$ & Octahedron & -8 \\
$\mathrm{Ni}^{2+}$ & $\mathrm{d}^{8}$ & $70 \mathrm{pm}$ & Octahedron & -12 \\
$\mathrm{Cu}^{2+}$ & $\mathrm{d}^{9}$ & $69 \mathrm{pm}$ & Plane square & -12.3 \\
$\mathrm{Zn}^{2+}$ & $\mathrm{d}^{10}$ & $74 \mathrm{pm}$ & Tetrahedron & 0 \\
\hline
\end{tabular}

\subsection{Multistage Tandem Mass Spectrometry Analysis of $M^{2+} /$ Quercetin Complexes}

In order to obtain more structural information of $\mathrm{M}^{2+} /$ quercetin complexes and their relative stability, multistage tandem mass spectrometry was used to characterize the $\mathrm{M}^{2+} /$ quercetin (molar ratio of $\mathrm{Q} / \mathrm{M}=$ 2:1) complexes. The resulting spectra can provide important structural information regarding these 
complexes, which are very useful to further explore the dissociation mechanism and stabilities of the quercetin-metal complexes.

As shown in Figure 2a, the CID spectrum of the quercetin-Fe complex A $(\mathrm{m} / z$ 658, molar ratio of $\mathrm{Q} / \mathrm{Fe}=2: 1$ ), Figure $2 \mathrm{a}$ produced a lot of information with the generation of considerable product ions by a series of neutral losses, such as losses of $\mathrm{CO}$ and the $\mathrm{H}_{2} \mathrm{O}$, as well as cleavages of the C-ring and chelating bonds.

These product ions were extremely important in inferring the chelating positions of the $\mathrm{M}^{2+} /$ quercetin complexes. Eight ions at $m / z 640,630,612,602,584,508,465$, and 375 were present in the $\mathrm{MS}^{2}$ spectrum: the ion at $\mathrm{m} / z 640$ was derived from the neutral loss of $\mathrm{H}_{2} \mathrm{O}(-18 \mathrm{Da})$; the most intensive product ion $(\mathrm{m} / \mathrm{z} 630)$ came from the neutral loss of $\mathrm{CO}(-28 \mathrm{Da})$; The peaks at $\mathrm{m} / \mathrm{z} 612,602$ and 584 were corresponding to the ions $\left[\mathrm{A}-\mathrm{H}_{2} \mathrm{O}-\mathrm{CO}\right]^{+},[\mathrm{A}-2 \mathrm{CO}]^{+}$and $\left[\mathrm{A}-2 \mathrm{CO}-\mathrm{H}_{2} \mathrm{O}\right]^{+}$, respectively. The cleavage of C ring (retro Diels-Alder (RDA) reaction) of quercetin yielded the ion at $\mathrm{m} / \mathrm{z} 508$ by a neutral loss of $150 \mathrm{Da}$ from the parent ion at $\mathrm{m} / \mathrm{z} 658$, and the $\mathrm{m} / \mathrm{z} 508$ ion was prone to the loss of one $\mathrm{CO}_{2}$ to produce the ion at $m / z 465$.

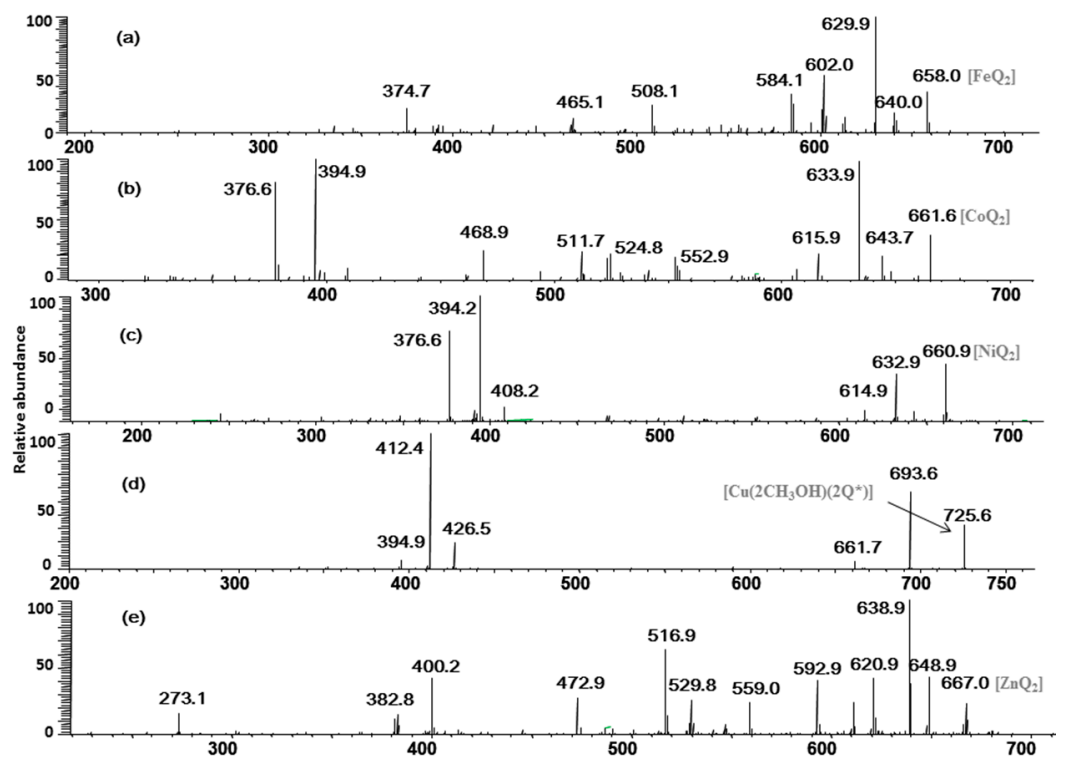

Figure 2. $M S / M S$ spectrum of the quercetin $/ \mathrm{M}^{2+}$ complexes $\left(\mathrm{Q} / \mathrm{M}^{2+}=2: 1\right)$. (a)-(e) for quercetin-Fe, $-\mathrm{Co},-\mathrm{Ni},-\mathrm{Cu}$, and - $\mathrm{Zn}$ complexes, respectively.

In the pathway of losing a quercetin aglycone (-302 Da), the $m / z 375$ ion is produced. Besides, it is reported that there are three possible complexation sites between metal ions and quercetin [29,30] (Scheme 1). The net charge $(q)$ and charge density edge (Q and $\mathrm{QR}$ ) of the primary coordination atoms $[29,30]$, which are very important in determining the complexation sites, are summarized in Table 2. From the above results, it can be deduced that quercetin formed different complexes by its 5-OH and 4-carbonyl with these metal divalent ions, which is the most favorable fragmentation pathway, because it does not involve the cleavage of the chelating bonds in the RDA reaction. These results further indicated that the above metal divalent ion can form stable complexes in solution. For example, if complex A were just a simple adduct of the $\mathrm{Fe}^{2+}$ and quercetin (e.g., 1:2 complexes), some simple decomposition product ions should be observed. Based on the above discussion, the fragmentation mechanism of the quercetin-Fe complex A was proposed in Scheme 2. 


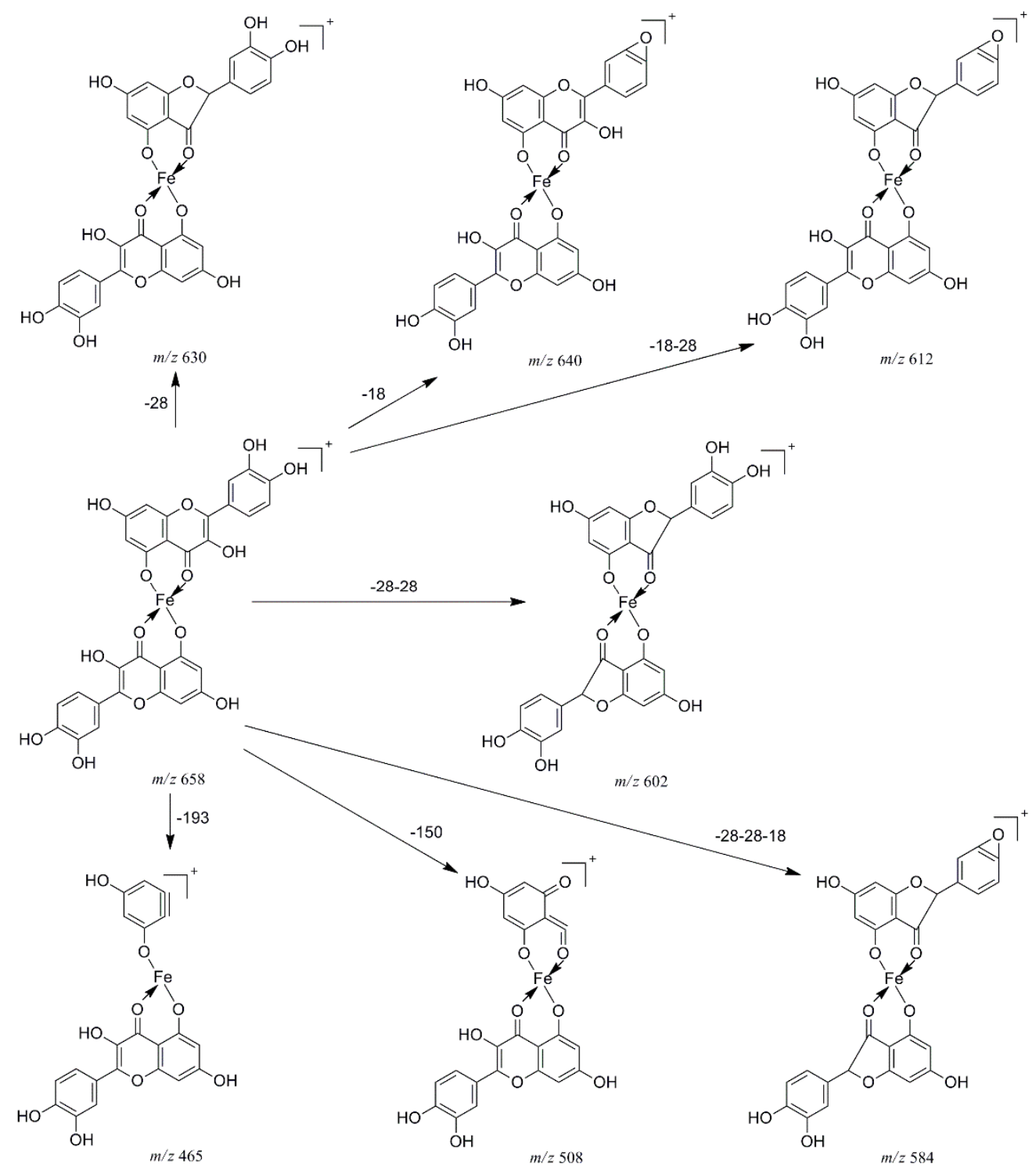

Scheme 2. Proposed fragmentation mechanism of the quercetin-Fe complex A $(\mathrm{m} / z$ 658).

Table 2. Charge density and net charge density of primary coordination atoms in flavonoids.

\begin{tabular}{cccc}
\hline Atom & Net Charge $(\boldsymbol{q})$ & $\begin{array}{c}\text { Charge Density } \\
\text { Edge }(\mathbf{Q})\end{array}$ & $\begin{array}{c}\text { Energy-Weighted Charge } \\
\text { Density Edge (QR) }\end{array}$ \\
\hline O-3 & -0.3712 & 0.0709 & -0.1814 \\
O-5 & -0.3948 & 0.0018 & -0.0046 \\
O-3' & -0.3708 & 0.0422 & -0.1081 \\
O-4' & -0.3705 & 0.0169 & -0.0432 \\
\hline
\end{tabular}

The fragmentation pathways of quercetin-Co, -Ni, and $-\mathrm{Zn}$ complexes $(\mathrm{m} / \mathrm{z} 662,661$ and 667) are quite similar. In Figure $2 \mathrm{~b}-\mathrm{e}$ for example, we took the CID spectrum of the quercetin-Zn complex $\mathrm{H}$ $(\mathrm{m} / z$ 667, molar ratio of $\mathrm{Q} / \mathrm{Zn}=2: 1$, Figure 1e to explain their dissociation mechanism and infer their complexation sites.

The MS/MS spectrum of the quercetin-Zn complex $\mathrm{H}(\mathrm{m} / \mathrm{z} 667$, molar ratio of $\mathrm{Q} / \mathrm{Zn}=2: 1)$, in Figure $2 \mathrm{e}$ also yielded abundant product ions, including a series of ions with neutral losses, such as losses of CO and the $\mathrm{H}_{2} \mathrm{O}$, as well as cleavages of the C-ring and chelating bonds. Almost all types of neutral losses 
of quercetin-Fe complex A was reproduced in the $\mathrm{MS}^{2}$ spectrum of the complex $\mathrm{H}$, and the CID data of which was summarized in Scheme $3 \mathrm{a}$. However, $\mathrm{Zn}^{2+}$ has greater polarizability than that of $\mathrm{Fe}^{2+}$ because it contains more $d$-electrons, and the quercetin-Zn complex produced more product ions than that of the quercetin-Fe complex. For instance, the peak at $\mathrm{m} / \mathrm{z} 559$ was produced by the loss of B ring of quercetin from $\mathrm{m} / \mathrm{z}$ 667, and the ion at $\mathrm{m} / \mathrm{z} 531$ came from a further loss of CO from $\mathrm{m} / \mathrm{z} 559$; the other product ions, $m / z 401$ and $m / z 274$, arose from a loss of $266 \mathrm{Da}$ and $394 \mathrm{Da}$ from $m / z 667$, respectively. The CID spectra of quercetin-Co and quercetin-Ni complexes were almost identical with that of quercetin- $\mathrm{Zn}$ complex, which were shown in Figure 2b,c, respectively.

Interestingly, $\mathrm{Cu}^{2+}$ displayed quite different dissociation mechanism as compared with other divalent ions above $\left(\mathrm{Ni}^{2+}, \mathrm{Co}^{2+}, \mathrm{Fe}^{2+}\right.$ and $\left.\mathrm{Zn}^{2+}\right)$. This is partially because that $\mathrm{Cu}^{2+}$ has stronger oxidative activity, and quercetin is easier to be oxidized under acidic conditions. The possible oxidization sites of quercetin when oxidized by $\mathrm{Cu}^{2+}$ were reported as shown in Scheme 4 [23]. Obviously, quercetin could only form complexes with $\mathrm{Cu}^{2+}$ through $5-\mathrm{OH}$ and $4-\mathrm{C}=\mathrm{O}$ once it was oxidized. In the $\mathrm{CID}$ spectrum of the quercetin- $\mathrm{Cu}$ complex $\mathrm{G}(\mathrm{m} / \mathrm{z} 725$, molar ratio of $\mathrm{Q} / \mathrm{Cu}=2: 1)$, shown in Figure 2 d, five major product ions (at $m / z$ 693, 661, 426, 412 and 394) were observed. The parent ions $m / z 725$ lost one and two $\mathrm{CH}_{3} \mathrm{OH}$ molecules to produce the $m / z 693$ and 661 ions, respectively (Scheme 3b). In fact, small molecules $\left(\mathrm{H}_{2} \mathrm{O}\right.$, $\mathrm{CH}_{3} \mathrm{OH}$, etc.) adducts of metal complexes were usually found in the mass spectrometry [31].

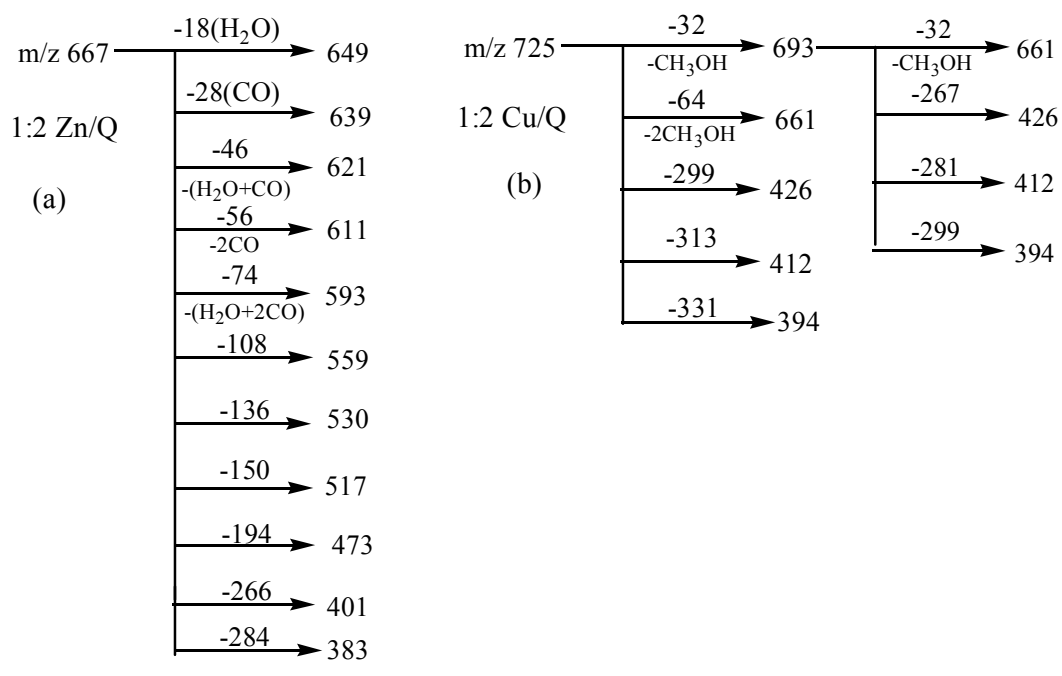

Scheme 3. MS/MS Data analysis for 1:2 Zn/Q (a) and Cu/Q complexes (b).

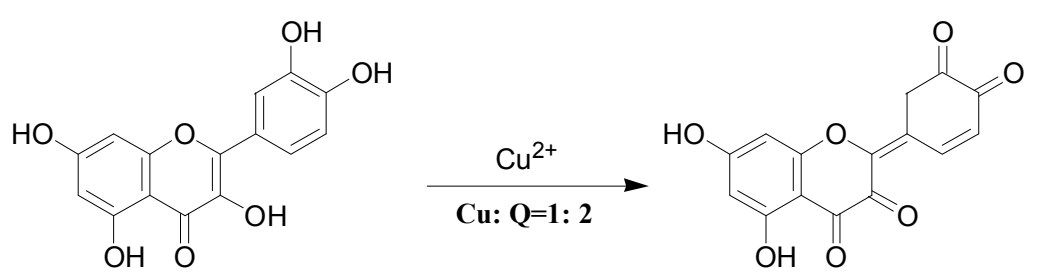

Scheme 4. Oxidized structure proposed for quercetin by $\mathrm{Cu}^{2+}$.

According to the masses of most fragments, we proposed that the ion at $m / z 426$ was derived from the neutral loss of an oxidized quercetin aglycone (-299 Da); the product ion at $\mathrm{m} / \mathrm{z} 412$ with the highest abundance was due to the neutral loss of one oxidized quercetin aglycone and the $-\mathrm{CH}_{2}$ groups of methanol $(-313 \mathrm{Da}=(-299 \mathrm{Da})+(-14 \mathrm{Da}))$; the ion at $\mathrm{m} / z 394$ corresponded to the neutral loss of an 
oxidized quercetin aglycone and the adduct methanol molecule $(-331 \mathrm{Da}=(-299 \mathrm{Da})+(-32 \mathrm{Da}))$ (Scheme 3b). These inferences further suggested that three hydroxyl groups in quercetin had been oxidized in this process: quercetin was first oxidized by $\mathrm{Cu}^{2+}$ to produce the quercetin stable oxide, then it formed a 2:1 complex with $\mathrm{Cu}^{2+}$ through 5-OH and 4-C=O, and two methanol molecules were added to the quercetin- $\mathrm{Cu}$ complex. To investigate the above speculation, we performed an additional $\mathrm{MS}^{3}$ experiment on the $m / z 693$ ion. The resulting spectrum is shown in Figure 3. In this spectrum, four stable product ions at $\mathrm{m} / \mathrm{z} 661,425,412$, and 394 were observed.

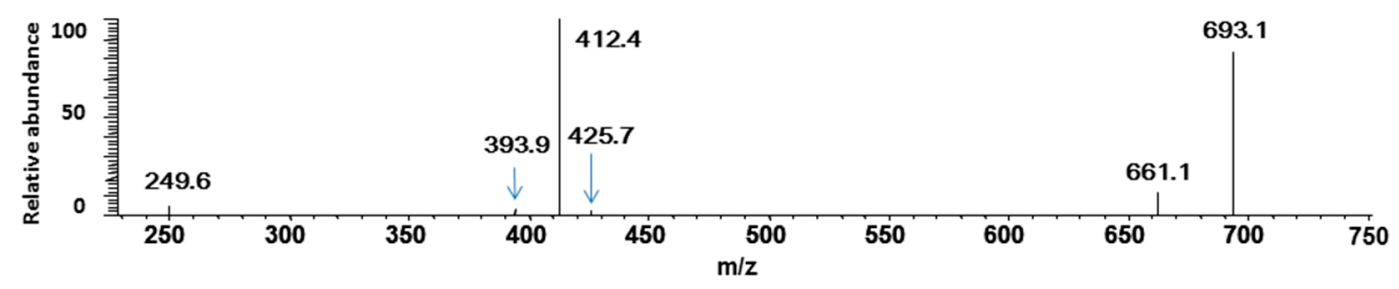

Figure 3. $\mathrm{MS}^{3}$ spectrum of $\mathrm{Cu}^{2+} / \mathrm{Q}$ complex $\mathrm{M}(725>693>)$.

In summary, our studies showed that quercetin was able to form a series of metal-flavonoid complexes through its 5-OH and 4-carbonyl groups with all of the first transition divalent metal ions $\left(\mathrm{Fe}^{2+}, \mathrm{Co}^{2+}, \mathrm{Ni}^{2+}, \mathrm{Cu}^{2+}\right.$ and $\left.\mathrm{Zn}^{2+}\right)$. The stabilities and chelating sites of these metallic complexes were highly dependent on the properties of both the metallic ions and the flavonoid chelator, and could be successfully characterized by means of ESI-MS ${ }^{\mathrm{n}}$.

\section{Experimental Section}

\subsection{Reagents and Chemicals}

Standard quercetin was purchased from National Institutes for Food and Drug Control (Beijing, China). All the salts used in this study $\left(\mathrm{FeCl}_{2} \cdot 4 \mathrm{H}_{2} \mathrm{O}, \mathrm{CoCl}_{2} \cdot 6 \mathrm{H}_{2} \mathrm{O}, \mathrm{NiCl}_{2} \cdot 6 \mathrm{H}_{2} \mathrm{O}, \mathrm{CuCl}_{2} \cdot 2 \mathrm{H}_{2} \mathrm{O}\right.$ and $\left.\mathrm{ZnCl}_{2}\right)$ as well as the solvents $(\mathrm{MeOH})$ were of analytical purity without further purification.

\subsection{Sample Preparation}

The quercetin standard and five transition metal chlorides $\left(\mathrm{FeCl}_{2} \cdot 4 \mathrm{H}_{2} \mathrm{O}, \mathrm{CoCl}_{2} \cdot 6 \mathrm{H}_{2} \mathrm{O}, \mathrm{NiCl}_{2} \cdot 6 \mathrm{H}_{2} \mathrm{O}\right.$, $\mathrm{CuCl}_{2} \cdot 2 \mathrm{H}_{2} \mathrm{O}$ and $\mathrm{ZnCl}_{2}$ ) were dissolved in methanol with a final concentration of $10 \mu \mathrm{M}$. Methanol solution of quercetin was mixed with five kinds of transition metal salt solutions with equal volume in the test tubes, respectively. Then the tubes were sealed. After 30 min ultrasonic treatment, the solution was subjected to mass spectrometry analysis.

\subsection{Mass Spectrometry}

All of the mass spectrometric experiments were performed on a Finnigan MAT LCQ ${ }^{\mathrm{TM}}$ mass spectrometer (Finnigan, San Jose, CA, USA). Before each experiment, the instrument was calibrated using standard chemicals (caffeine, peptide MFRA and Ultramark 1621), and tuned following protocols provided by the instrument manufacturer. The scan range was from $\mathrm{m} / \mathrm{z} 50$ to 2000 with unit mass resolution, and the infusion rate was $3 \mu \mathrm{L} / \mathrm{min}$. The spray voltage was set to $4.8 \mathrm{kV}$, and the capillary 
temperature was $180{ }^{\circ} \mathrm{C}$. In the $\mathrm{MS}^{\mathrm{n}}$ experiments, helium was used as collision gas, and the mass isolation width was $2.0 \mathrm{Da}$.

\section{Conclusions}

Metal flavonoid complexes are a promising class of natural drug leads, and the associated studies have attracted more and more attention. However, the systematic basic research of metal-flavonoid complexes is lagging behind, partly because very few efforts have been made to establish a set of activity screening and subsequent evaluation system for the comprehensive investigations on the structure and activity relationship of metal-flavonoid complexes.

The effects of the number of $d$-electrons of the first transition metals on the formation and stability of metal-flavonoid complexes were systematically investigated in the present study. Although the formation of flavonoid-transition metal complexes is quite complicated, our results showed that ESI-MS $^{\mathrm{n}}$ can be used to study these complexes with several obvious advantages. First, the complexes can be detected in solution with high sensitivity. Not only can this technique provide direct evidence for the formation of the complexes in the solution, but can also be easily used to explore the information on the composition and stoichiometry of the complexes based upon the masses of complex ions and fragmentation ions of the complexes of interest. Second, the relative stabilities of complexes may be determined by means of the relative CID energies under the same experimental condition, which is very important in establishing a fast screening system for metal-flavonoid complexes. More importantly, ESI-MS $^{\mathrm{n}}$ can facilitate the determination of the complexation sites of the complexes, even of other side reactions (e.g., oxidization reaction) during the complexation process, thus provided a highly sensitive and fast screening method in exploring the structure and property of these interesting complexes.

Using ESI-MS ${ }^{\mathrm{n}}$ to characterize the metal-flavonoid complexes, we found that all of the first transition metallic ions $\left(\mathrm{Fe}^{2+}, \mathrm{Co}^{2+}, \mathrm{Ni}^{2+}, \mathrm{Cu}^{2+}\right.$ and $\mathrm{Zn}^{2+}$ ) can form complexes with quercetin; the number of chelating flavonoids decreases along with the reduction of the metal ionic radius. Quercetin forms different complexes with the above metal divalent ion through its 5-OH and 4-carbonyl groups; the complex stability is highly dependent on both the metallic ion and the flavonoid chelator. As for the central ion $\left(\mathrm{M}^{2+}\right)$, when chelated with quercetin to form the complex, it has the following order in stability: $\mathrm{Cu}^{2+}>\mathrm{Ni}^{2+}>\mathrm{Co}^{2+}>\mathrm{Fe}^{2+}>\mathrm{Zn}^{2+}$. With stoichiometry of flavonoid: metal at 2:1, the complexes formed between quercetin and metal ions $\left(\mathrm{Fe}^{2+}, \mathrm{Ni}^{2+}, \mathrm{Co}^{2+}\right.$ and $\mathrm{Zn}^{2+}$ ) have similar dissociation mechanisms. However, $\mathrm{Cu}^{2+}$ displayed a different dissociation mechanism, mainly because of its relatively stronger oxidation capacity, and ESI-MS ${ }^{\mathrm{n}}$ can readily examine this oxidation process. Thus, our study could be easily expanded to the analysis of other types of metal-flavonoid complexes, even other metallic complexes, and may greatly contribute to a better understanding of the chelating chemistry of flavonoids with transition metal ions and beyond, and further promote the research in the potential drug discovery and development from flavonoid metal complexes.

\section{Acknowledgments}

The research was supported in part by "the Hundred Talents Program" from Chinese Academy of Sciences (Grant No. 29Y429291a0129 to M. Guo), and the Sino-Africa joint research project (Grant No. 23 Y323751a0275 to M. Guo). Both funders played no roles in the study design, data collection and 
analysis, and decision to publish, or preparation of the manuscript. Meanwhile, the authors would like to thank S.Y. Liu, Z.Q. Liu and F.R. Song for their support and valuable discussions in this study.

\section{Author Contributions}

The list of authors contributed to this work as follows: M. Guo conceived and designed the experiments, Y. Liu performed the experiments and analyzed the data, Y. Liu and M. Guo wrote the paper, and M. Guo polished the data. Both authors read and approved the final manuscript.

\section{Conflicts of Interest}

The authors declare no conflict of interest.

\section{References}

1. Corradini, E.; Foglia, P.; Giansanti, P.; Gubbiotti, R.; Samperi, R.; Lagana, A. Flavonoids: Chemical properties and analytical methodologies of identification and quantitation in foods and plants. Nat. Prod. Res. 2011, 25, 469-495.

2. Guardia, T.; Rotelli, A.E.; Juarez, A.O.; Pelzer, L.E. Anti-inflammatory properties of plant flavonoids. Effects of rutin, quercetin and hesperidin on adjuvant arthritis in rat. Il Farmaco 2001, 56, 683-687.

3. Mira, L.; Fernandez, M.T.; Santos, M.; Rocha, R.; Florencio, M.H.; Jennings, K.R. Interactions of flavonoids with iron and copper ions: A mechanism for their antioxidant activity. Free Radic. Res. 2002, 36, 1199-208.

4. Grazul, M.; Budzisz, E. Biological activity of metal ions complexes of chromones, coumarins and flavones. Coord. Chem. Rev. 2009, 253, 2588-2598.

5. Afanas'ev, I.B.; Ostrakhovitch, E.A.; Mikhal'chik, E.V.; Ibragimova, G.A.; Korkina, L.G. Enhancement of antioxidant and anti-inflammatory activities of bioflavonoid rutin by complexation with transition metals. Biochem. Pharmacol. 2001, 61, 677-684.

6. Cheng, I.F.; Breen, K. On the ability of four flavonoids, baicilein, luteolin, naringenin, and quercetin, to suppress the Fenton reaction of the iron-ATP complex. Biometals 2000, 13, 77-83.

7. Kostyuk, V.A.; Potapovich, A.I.; Strigunova, E.N.; Kostyuk, T.V.; Afanas'ev, I.B. Experimental evidence that flavonoid metal complexes may act as mimics of superoxide dismutase. Arch. Biochem. Biophys. 2004, 428, 204-208.

8. Chen, W.J.; Sun, S.F.; Cao, W.; Liang, Y.; Song, J.R. Antioxidant property of quercetin-Cr(III) complex: The role of Cr(III) ion. J. Mol. Struct. 2009, 918, 194-197.

9. Bravo, A.; Anacona, J.R. Metal complexes of the flavonoid quercetin: Antibacterial properties. Transit. Metal Chem. 2001, 26, 20-23.

10. Zhou, J.; Wang, L.F.; Wang, J.Y.; Tang, N. Antioxidative and anti-tumour activities of solid quercetin metal(II) complexes. Transit. Metal Chem. 2001, 26, 57-63.

11. Mendoza, E.E.; Burd, R. Quercetin as a Systemic Chemopreventative Agent: Structural and Functional Mechanisms. Mini-Rev. Med. Chem. 2011, 11, 1216-1221. 
12. Malesev, D.; Kuntic, V. Investigation of metal-flavonoid chelates and the determination of flavonoids via metal-flavonoid complexing reactions. J. Serb. Chem. Soc. 2007, 72, 921-939.

13. Cornard, J.P.; Merlin, J.C. Spectroscopic and structural study of complexes of quercetin with Al(III). J. Inorg. Biochem. 2002, 92, 19-27.

14. Yamashita, N.; Tanemura, H.; Kawanishi, S. Mechanism of oxidative DNA damage induced by quercetin in the presence of $\mathrm{Cu}(\mathrm{II})$. Mutat. Res. 1999, 425, 107-115.

15. Torreggiani, A.; Tamba, M.; Trinchero, A.; Bonora, S. Copper(II)-quercetin complexes in aqueous solutions: Spectroscopic and kinetic properties. J. Mol. Struct. 2005, 744, 759-766.

16. El Hajji, H.; Nkhili, E.; Tomao, V.; Dangles, O. Interactions of quercetin with iron and copper ions: Complexation and autoxidation. Free Radic. Res. 2006, 40, 303-320.

17. Leopoldini, M.; Russo, N.; Chiodo, S.; Toscano, M. Iron chelation by the powerful antioxidant flavonoid quercetin. J. Agric. Food Chem. 2006, 54, 6343-6351.

18. Xu, G.R.; In, Y.M.; Yuan, Y.; Lee, J.J.; Kim, S. In situ spectroelectrochemical study of quercetin oxidation and complexation with metal ions in acidic solutions. Bull. Korean Chem. Soc. 2007, 28, 889-892.

19. Jurasekova, Z.; Torreggiani, A.; Tamba, M.; Sanchez-Cortes, S.; Garcia-Ramos, J.V. Raman and surface-enhanced Raman scattering (SERS) investigation of the quercetin interaction with metals: Evidence of structural changing processes in aqueous solution and on metal nanoparticles. J. Mol. Struct. 2009, 918, 129-137.

20. Dehghan, G.; Dolatabadi, J.E.N.; Jouyban, A.; Zeynali, K.A.; Ahmadi, S.M.; Kashanian, S. Spectroscopic Studies on the Interaction of Quercetin-Terbium(III) Complex with Calf Thymus DNA. DNA Cell Biol. 2011, 30, 195-201.

21. Dolatabadi, J.E.N. Molecular aspects on the interaction of quercetin and its metal complexes with DNA. Int. J. Biol. Macromol. 2011, 48, 227-233.

22. Zhang, Y.P.; Shi, S.Y.; Sun, X.R.; Xiong, X.; Peng, M.J. The effect of $\mathrm{Cu}^{2+}$ on interaction between flavonoids with different C-ring substituents and bovine serum albumin: Structure-affinity relationship aspect. J. Inorg. Biochem. 2011, 105, 1529-1537.

23. Fernandez, M.T.; Mira, M.L.; Florencio, M.H.; Jennings, K.R. Iron and copper chelation by flavonoids: An electrospray mass spectrometry study. J. Inorg. Biochem. 2002, 92, 105-111.

24. Satterfield, M.; Brodbelt, J.S. Enhanced detection of flavonoids by metal complexation and electrospray ionization mass spectrometry. Anal. Chem. 2000, 72, 5898-5906.

25. Pikulski, M.; Brodbelt, J.S. Differentiation of flavonoid glycoside isomers by using metal complexation and electrospray ionization mass spectrometry. J. Am. Soc. Mass Spectrom. 2003, 14, $1437-1453$.

26. Dowling, S.; Regan, F.; Hughes, H. The characterisation of structural and antioxidant properties of isoflavone metal chelates. J. Inorg. Biochem. 2010, 104, 1091-1098.

27. Pekal, A.; Biesaga, M.; Pyrzynska, K. Interaction of quercetin with copper ions: Complexation, oxidation and reactivity towards radicals. Biometals 2011, 24, 41-49.

28. Housecroft, C.E.; Sharpe, A.G. Inorganic Chemistry, 2nd ed.; Ashford Colour Press: London, UK, 2005.

29. Katyal, M. Flavones as Analytical Reagents-A Review. Talanta 1968, 15, 95-106.

30. Katyal, M.; Prakash, S. Analytical Reactions of Hydroxyflavones. Talanta 1977, 24, 367-375. 
31. Satterfield, M.; Brodbelt, J.S. Structural characterization of flavonoid glycosides by collisionally activated dissociation of metal complexes. J. Am. Soc. Mass Spectrom. 2001, 12, 537-549.

Sample Availability: Samples are not available from the authors.

(C) 2015 by the authors; licensee MDPI, Basel, Switzerland. This article is an open access article distributed under the terms and conditions of the Creative Commons Attribution license (http://creativecommons.org/licenses/by/4.0/). 